\title{
Microfinance Institutions in Nigeria: Issues and Research Areas
}

\author{
Nasiru Liman Zuru \\ Mohd Khairuddin Hashim \\ Darwina Arshad
}

College of Business, Universiti Utara Malaysia

\section{Doi:10.5901/mjss.2016.v7n2s1p455}

\begin{abstract}
Microfinance institutions (MFIs) in Nigeria are considered as key players in the microfinance industry in the country. While these institutions are recognized for their significant role in the microfinance industry, as a field of study, MFls appear to have not been able to attract much research emphasis. The review of past research suggests that both theoretical and empirical contributions in this field remained restricted, particularly in the context of Nigeria. This paper reviews previous works on microfinance in an attempt to identify the issues and provides some suggestions for further research on MFIs in Nigeria. More specifically, the paper emphasizes on the issues neglected in past studies as well as focuses on some of the research areas in the field of MFIs that need to be addressed and investigated empirically.
\end{abstract}

Keywords: Microfinance, Institutions, Issues, Research, and Nigeria

\section{Introduction}

Funding provided by microfinance institutions (MFIs) is increasingly being viewed as an important source of financing for people with limited income as well as those who do not have access to banking and other conventional financial services. More importantly, in developing countries such as Bangladesh and Nigeria, the financial services offered by MFIs are considered not only beneficial to the poor people but also useful in terms of helping to eradicate poverty in these countries (Shukran \& Rahman, 2011; Tadele \& Rao, 2014; Yunus, 1998, 2007).

Even though being recognized as an essential component of the financial ecosystem in developing countries such as Nigeria, MFIs as a field of study has not been able to attract much research attention. Despite their complexity as well as significant role in the national economy of Nigeria, research on MFIs appears to be narrowed and ignored. The literature indicates that MFIs have attracted minimal theoretical and empirical studies as an area of research. The review of the literature and past studies suggests the lack of investigations on MFIs and also indicates various gaps in the information and knowledge about the MFIs in Nigeria.

In addition, a review of the findings of prior research unveils that previous studies are subjected to several drawbacks and also information obtained from these studies does not appear to have been able to provide a framework for better understanding of the MFIs sector. In view of the various limitations and issues identified in past studies as well as the detection of research areas pertaining to MFIs, there is a need to develop a new research agenda for investigating MFIs in Nigeria. By attempting to address this need, this paper aims to spearhead the development of purposeful research on MFIs in Nigeria.

The present paper is organized into five sections. The following Sections Two and Three highlight the research issues that need to be dealt with before proper studies on MFls should be conducted. Next, Section Four highlights the limitations of the scope and research focus of previous works on MFIs in Nigeria. Based on the findings in these sections, Section Five proposes a research agenda for examining MFIs. Lastly, the conclusion of the paper is presented in Section Six.

\section{Research Issues Concerning MFIs}

As far as the MFIs are concerned, the authors have identified two conceptual issues related to their operational definitions that need to be clarified not only by researchers but also by policy makers. The two conceptual issues are briefly explained below: 


\subsection{The concept of Microfinance}

Microfinance institutions (MFIs) provide micro financing to their clients. The MFIs are created and funded by non-profit organizations, government agencies, individuals, local community and large financial institutions. In general, the term microfinance has been defined in two different ways. The first definition refers to microfinance as small loans or microloan offered to poor people or those individuals who have very low income or are self-employed (Olanike \& Adebola 2014). However, the other common definition of microfinance has a broader meaning. According to the second definition, apart from the small amount of loans given out, the other services related to finance such as credit, savings, insurance and fund transfers are also considered as important components of microfinance (Al-Shami et al., 2014). As far as research on microfinance is concerned, the review of previous studies appears to indicate that most of the studies tend to mainly investigate microfinance as small loans borrowed by the poor (Microfinance Information Exchange, Inc., 2010).

\subsection{Types of MFIs}

The more recent estimates from the World Bank suggest that there are more than 7,000 MFIs worldwide and that these institutions served more than 16 million clients as well as provided a total of US $\$ 2.25$ billion in loans and other financial assistance (Businessnewsdaily, 2013). In addition, it is equally important to know that although MFIs are found in many developing countries, they differ greatly in their nature and importance. For instance, in Nigeria alone, there are five types of MFIs. They include; the MFIs owned by the local community, the private initiated MFIs, the government funded MFIs, the MFIs owned by the non-government organizations and the foreign owned MFIs (Central Bank of Nigeria, 2015). In other words, MFIs are not homogenous but heterogeneous. Given this, researchers should emphasize on their different types when investigating MFIs.

\section{Issues Identified from Past Studies on MFls}

Over the years, even though MFIs in Nigeria appears to have been able to attract increasing research attention, empirical studies on these institutions are still relatively limited in terms of their scope as well as focus. At the general level, the research focus has been primarily on reporting and describing their intellectual capital, information communication technology (ICT) adoption, capital structure, corporate governance, and effectiveness of the financial schemes on the reduction of poverty (Abraham \& Balogun, 2012; Amoo \& Kolawole, 2015; Ashamu \& Ayodele, 2015; Chinasa, 2015; Ikpefan, Kazeem, \& Taiwo, 2015; Kasali, Ahmad, \& Ean, 2015; Olasupo, Afolami, \& Shittu, 2014; Oludare \& Oyedele, 2015; Onugu Uchenna, Obianuju, \& Kamaldeen, 2015; Owolabi, 2015; Paul \& Emesuanwu Catherine Ebelechukwu, 2015; Ringim, Razalli, \& Hasnan, 2012; Waithaka, Gakure, \& Wanjau, 2013).

Accordingly, the following section presents the common characteristics and shortcomings of past research on MFIs as identified in prior studies.

\subsection{Business Practices and Performance of MFIs}

The literature suggests that effective business practices are related to organizational performance. Both previous conceptual as well as empirical studies have provided the evidence that indicate the linkage between business practices and organizational performance (Hashim, 2012; Marcus, 2006). However, the review of past studies indicates that there is not only little information on the business practices adopted by the MFIs but also the relationships between business practices and performance of MFIs have not been established, particularly in the Nigerian context (Abraham \& Balogun, 2012; Olanike \& Adebola, 2014).

\subsection{Business Strategy in MFIs}

Business strategy is essential to the success of all organizations. Business enterprises such as microfinance institutions need to develop effective business strategy in order to sustain their organizational performance and operations. However, the review suggests that there is little information about the business strategy adopted the MFIs in Nigeria. The review further reveals that barely any research attempt has been made to investigate MFIs from the business strategy perspective. Despite the increased knowledge in the area of business strategy, little research exists that examines the business strategy formulated and implemented by the MFIs. The lack of information and knowledge concerning business strategy adopted by the MFIs in Nigeria justified for more studies to focus on this important area of research (Vanroose \& D'Espallier, 2013). 


\subsection{Competition among the MFIs}

Like other business organizations, MFIs have to compete with other organizations for various resources. The most common resource that business organizations compete for are customer dollars. More importantly, it is essential for management of MFIs to know, understand, and appreciate that competition is usually complex. The MFIs should be alert to the competitive environment and careful enough not to oversimplify the information about it that flows into their organization. Some information about competition is often quite easily to get. Meanwhile, other kinds of information about competition may be more difficult to obtain. Although the literature also suggests that competition can influence organizational performance, very few studies have actually investigated the intensity of competition in the microfinance industry in Nigeria as well determine the impact of competition on the performance of MFIs (Assefa, Hermes, \& Meesters, 2013; Vanroose \& D’Espallier, 2013).

\subsection{Omission of Theories in the Study of MFIs}

Despite the tremendous increase in knowledge and theories in the areas of management such as finance, marketing, human resource, and strategic management, not much of these management theories have been adopted by researchers in investigating MFIs. For example, although strategic management is applicable and relevant to MFIs, there has been limited attempt to study these organizations from the strategic management perspective in Nigeria.

\subsection{Lack of Entrepreneurial Approach}

In an earlier study, Jennings (1994) pointed that the success of an individual organization depends on various factors that can only be observed at different levels of analysis. Nevertheless, the literature indicates the lack of entrepreneurial approach as well as multi-level research design in the study of MFIs in Nigeria. The review of past studies seems to indicate that previous research that examined MFIs tend to analyze these institutions primarily from the organizational level (either individual level or organizational level). This single level of analysis may result in the researcher overlooking other key factors that can affect the success of MFIs at different levels of analysis.

\section{Research Agenda for Studying MFIs in Nigeria}

Having identified the shortcomings and limitations of past research on MFIs as documented in the literature and past studies, this paper proposed the following research agenda.

\subsection{Appropriate Operational Definition of Microfinance and MFIs}

As shown earlier, currently there is no one overall acceptable standard definition of MFIs. In practice, the definitions of MFIs are based on the types of financial services they provided to their clients. However, given the uniqueness of MFIs (in terms of their ownerships, resources and management styles for instance), any definition based on just financial services is believed to be inappropriate to describe and measure satisfactorily the true nature of MFIs in Nigeria.

Defining MFIs appropriately is important because it has serious implications on the directions of research to be conducted and the formulation and implementation of the related policies. In other words, a precise and more appropriate definition that reflects the ownership, size, the nature and the needs of MFls is essential and advantageous not only for a particular MFI, but also for policy makers and supporting agencies in planning and nurturing the proper growth and development of the MFIs sector as a whole.

Given the importance of a precise and more appropriate definition of MFIs, this paper suggests that more empirical studies should focus in this area. Attempts to define MFIs appropriately should not only be based on quantitative criteria but also qualitative criteria should also be taken into consideration to reflect the true nature of MFIs.

\subsection{Developing MFIs Taxonomies in Nigeria}

Microfinance institutions (MFIS) consist of different types of organizations and they serve a wide range of clients/customers. It is generally believed that the presence of different types of MFIs is the indication of imperfections in the economies in which MFIs exist. Developing taxonomies of MFIs is a prerequisite for explaining how MFIs in Nigeria differ from each other. This move can also further promote as well as facilitate research on these organizations. 


\subsection{Purpose of Research}

The review past studies appears to suggest that the purpose of previous studies on MFIs is generally limited in terms of their research focus as well as scope. Studies that have restricted research focus and scope are not able to provide useful insights into the true nature of the MFIs as well as the way they are managed. The limited research focus and scope may also restraint the information and knowledge on MFIs as a field of study. In this area, it is advocated that future research projects should include a clearer statement of purpose. It is also suggested that researchers attempt to expand their purpose of study by striving to explain the environmental as well as organizational factors that can influence their performance and their important role in eradicating poverty, particularly in the Nigerian context.

\subsection{Theoretical Orientation}

Meaningful and rigorously empirical research should include theory. As previously highlighted, previous research on MFIs has however neglected to study these organizations from the perspective of modern management theory. Despite the tremendous increase in knowledge in the areas of management theories, little research has been conducted to investigate the relevant and applicability of these theories to MFIs.

Although some researchers may claim that there is no one best theory to explain the business operations and growth of MFIs, it is about time that more research attempts be made to borrow theories from the other disciplines (such as management and economics theories) to help explain MFIs behavior. For instance, since MFIs are concerned with units of economic activity, attempts to borrow the theory of monopolistic competition can help to explain why certain MFls adopt different types of business strategy.

The various theories in the field of strategic management (such as contingency theory, resource-based view theory, socio-cultural theory, and the uncertainty-based theory) could be adopted to help understand, explain and predict MFIs behaviors. Moreover, by using induction and deduction reasoning, attempts can also be made to construct theories of MFIs.

\subsection{Focus on Methodological Issues}

The MFIs in Nigeria are heterogeneous in nature. They differ in types of ownerships, capital structures, in management styles and sophistication, in stages of development, and in their performance. Meanwhile, the research focus on MFIs in this country is very limited and confined to areas such as intellectual capital, information, communication and technology (ICT) adoption, capital structure, governance, marketing and effectiveness of the financial schemes.

Of the research that investigated MFIs in Nigeria, many suffer from methodological problems such as different types of samples used, used of secondary data, and divergent operational definitions of MFIs. As a result of these shortcomings, any attempt to develop a framework for understanding MFIs based on previous research would be futile.

\subsection{Level/Unit of Analysis}

As an important area of research, MFIs should be studied at five different levels of analysis. Given that they are not homogenous, these institutions should be study from multiple levels of analysis. Research on MFIs should focus on multiple levels of analysis that include the following; individual level (individual owners and managers of MFIs), organizational level (organizational perspective and factors), group level (similar or different types of MFIs), industry level (all the MFIs and from the perspective of the microfinance industry) and the level of society (impact of MFls on the society). Nevertheless, the literature review indicates that researchers in the area of MFIs in Nigeria have tended to not only avoid multilevel research but also emphasis on only a single level of analysis.

For instance, the relationships between the external factors, organizational factors and performance of MFIs can be studied by using multiple levels of analysis. Research that focus on multiple levels of analysis is able to provide both holistic and functional perspectives to not only scholars, but also useful for practitioners and public policy makers as well. In addition, according to the entrepreneurial perspective, the success of the individual enterprise will be affected by various factors that can only be examined at different levels of analysis. The omission of any one of these perspectives will make the owners and managers of the MFIs less aware of the essential internal and external factors that can influence their performance. Importantly, by adopting multiple levels of analysis, the policy makers will be able to obtain not only holistic and functional perspectives but also useful information that they can use to develop more effective assistance programs to promote and encourage the development of more successful MFIs. 
Given the importance to understand the different levels of analysis in the study of MFIs, it is suggested that future researchers examine these institutions by using multiple levels of analysis. The adoption of multilevel research can help to explain various perspectives of MFIs as well as provides new insights into these institutions and as such, should therefore be encouraged in future research projects.

\subsection{Longer Time Frame}

The review of past research reveals that prior studies has not emphasized on the need for wide time frame when investigating the various types of MFIs in Nigeria. Although in general, cross-sectional studies are easier to conduct, these one-short studies involve gathering data just once and at only one point in time. Results from this short time frame studies are normally less insightful than the findings of longitudinal studies that attempt to examine MFIs at more than one point in time. For instance, in the case of new MFIs, longer time frame is important because these institutions are extremely fragile and they often experience many changes as well as challenges within their short period of operations. Only by conducting longitudinal studies will the researchers be able to study and capture the effects and the challenges faced by the new MFIs.

Having underlined this issue, it is proposed that future research should move towards longer time frames (at least three to five years) since different strategic issues develop into fundamental as organizations and the industry in which they operate evolve.

\subsection{Suggested Research Methodology}

The review also suggests that there seems to be little research that focused on issues of causality in MFIs. Previous research mainly adopted short time frame studies that attempted to examine the variables that are associated to the performance of the MFIs. However, as a field of study and in order to keep pace with the development of MFIs in the microfinance industry, research in this area should also focus on cause and effect relationships. As the field of MFIs evolves, researchers should attempt to pursuit causality and longitudinal studies over cross sectional studies. The cross sectional studies are considered to be inappropriate for investigating MFIs since such methods are not able to provide the information needed to understand, explain, and predict the behaviors of MFIs.

\section{Conclusion}

This paper focuses on research in the field of microfinance institutions. The paper highlights not only important research issues in this field of study but also proposes a new research agenda for studying MFIs in Nigeria. Based on the review of the literature and past studies, this paper identifies several issues and proposes key research areas that need further empirical investigations to help us better understand as well as improve our knowledge in MFIs, especially those in operating in the microfinance industry in Nigeria.

The paper began by identifying and discussing the basic research issues concerning MFIs that need to be addressed before proper studies should be conducted. Following this, the proposed new research agenda is developed based on the various problems and shortcomings of the previous works on MFIs in Nigeria.

More specifically, it is proposed in the paper that as an important field of study, MFIs and microfinance should be appropriately defined, purposeful study on MFIs should be based on modern management or economic theory, that MFIs need to be investigated from multi-level and also future research should adopt wide time frame.

Lastly, in view that there is not much research emphasis given to MFIs previously, it is hoped that this paper has provided some contributions toward the development of a purposeful and rigorous research on MFIs, particularly in the context of Nigeria.

\section{References}

Abraham, H., \& Balogun, I. . (2012). Performance of microfinance institutions in Nigeria : an appraisal of self-reporting institutions to mix market. International Journal of Humanities and Social Science, 2(15), 32-50.

Al-Shami, S. S. A., Majid, A., Bin, I., Rashid, N. A., Hamid, B. A., \& Rizal, M. S. (2014). Conceptual framework: The role of microfinance on the wellbeing of poor people cases studies from Malaysia and Yemen. Asian Social Science, 1(1).

Amoo, Z. ., \& Kolawole, I. O. (2015). Contributions of microfinance banks to small and medium scale entrepreneurial development in Nigeria ( A case study of Lagos state ), 6(9), 35-39. 
Ashamu, O. S., \& Ayodele, O. J. (2015). An assessment of impact of microfinance banks on poverty alleviation in Nigeria : An empirical investigation. Journal of Policy and Development Studies, 9(2).

Assefa, E., Hermes, N., \& Meesters, A. (2013). Competition and the performance of microfinance institutions. Applied Financial Economics, 23(9), 767-782. doi:10.1080/09603107.2012.754541

Chinasa, W. E. (2015). Constraints to Women Entrepreneurs ' Access to Microfinance in Bayelsa state, Nigeria. Research Journal of Finance and Accounting, 4(6), 6-13.

Hashim, M. K. (2012). Business best practices: Unique or universal? Amity Business Journal, 1(1).

Ikpefan, O. A., Kazeem, B. L. O., \& Taiwo, J. . (2015). Human Capital Accounting and Performance of Microfinance Banks ( MFB ) in Nigeria. Journal of Finance and Accounting, 6(1), 65-76.

Jennings, D. F. (1994). Multiple perspectives of entrepreneurship: Text, readings and cases. Cincinnati: South-Western Publishing Co.

Kasali, T. A., Ahmad, S. A., \& Ean, L. H. (2015). The Role of Microfinance in Poverty Alleviation: Empirical Evidence from South-West Nigeria. Asian Social Science, 11(21), 183-192. doi:10.5539/ass.v11n21p183

Marcus, A. A. (2006). Big winners and big losers. New Jersey: Wharton School Publishing.

Olanike, B., \& Adebola, J. (2014). Prime lending rates and the performance of microfinance banks in Nigeria. Evaluation Review, 6(12), 131-137.

Olasupo, M. A., Afolami, C. A., \& Shittu, A. M. (2014). Productivity changes of microfinance research methodology. International Journal for Innovation Education and Research, 2, 43-51.

Oludare, F., \& Oyedele, O. (2015). Assessment of Microfinance Institutions as Poverty Reduction Mechanism in Nigeria. Journal of Accounting and Finance, 6(2), 18-27.

Onugu Uchenna, C., Obianuju, T. A. O. A., \& Kamaldeen, L. (2015). Assessing the extension service needs of credit officers of microfinance banks in Anambra state: Implications for rural finance intermediation. Asian Journal of Agriculture and Rural Development, 5(2).

Owolabi, O. E. (2015). Microfinance and poverty reduction in Nigeria: A case study of LAPO microfinance bank. University of Leeds.

Paul, G. D., \& Emesuanwu Catherine Ebelechukwu, S. Y. (2015). Impact of corporate governance on financial performance of microfinance banks in north central Nigeria. International Journal of Humanities Social Sciences and Education, 2(1). doi:10.5901/mjss.2014.v5n15p93

Ringim, K. J., Razalli, M. R., \& Hasnan, N. (2012). The relationship between information technology capability and organizational performance in Nigerian banks. International Journal of Technology and Management, 1(1), 1-10.

Shukran, K., \& Rahman, F. (2011). A Grameen bank concept : Micro-credit and poverty alleviation program in Bangladesh, 47-51.

Tadele, H., \& Rao, P. M. S. (2014, January 15). Corporate governance and ethical issues in microfinance institutions (MFIs) - A study of microfinance crises in Andhra Pradesh, India. Journal Of Business Management \& Social Sciences Research.

Vanroose, A., \& D'Espallier, B. (2013). Do microfinance institutions accomplish their mission? Applied Economics, 45(15), $1965-1982$.

Waithaka, S. M., Gakure, R., \& Wanjau, K. (2013). The effects of board characteristics on microfinance institutions ' social. Scientific Conference Proceedings, 362-381.

Yunus, M. (1998). Banker to the poor- micro-lending and the battle against world poverty (Vol. 4). Penguin Books India.

Yunus, M. (2007). Creating a world without poverty: Social business and the future of capitalism. PublicAffairs. 